\title{
Balkanologie
}

Balkanologie Revue d'études pluridisciplinaires

Vol. IX, n' 1-2 | 2005

Volume IX Numéro 1-2

\section{Les orthodoxies en Europe balkanique}

Introduction

Antonela Capelle-Pogǎcean et Kathy Rousselet

\section{OpenEdition}

Journals

Édition électronique

URL : https://journals.openedition.org/balkanologie/591

DOI : 10.4000/balkanologie.591

ISSN : 1965-0582

Éditeur

Association française d'études sur les Balkans (Afebalk)

Édition imprimée

Date de publication : 1 décembre 2005

ISSN : 1279-7952

Référence électronique

Antonela Capelle-Pogăcean et Kathy Rousselet, "Les orthodoxies en Europe balkanique »,

Balkanologie [En ligne], Vol. IX, n 1-2 | 2005, mis en ligne le 13 janvier 2010, consulté le 21 septembre

2021. URL : http://journals.openedition.org/balkanologie/591 ; DOI : https://doi.org/10.4000/

balkanologie.591

(c) Tous droits réservés 
Balkanologie IX (1-2), décembre 2005\213

\section{DOSSIER}

\section{LES ORTHODOXIES \\ EN EUROPE BALKANIQUE}




\title{
LES ORTHODOXIES EN EUROPE BALKANIQUE
}

\section{INTRODUCTION}

\author{
Antonela Capelle-Pogőcean \& Kathy Rousselet*
}

Ce dossier sur les orthodoxies en Europe balkanique est en partie issu d'une journée d'études organisée au Centre d'études et de recherches internationales (FNSP-CNRS) le 7 octobre 2005 et destinée à présenter un objet encore trop souvent ignoré dans sa complexité et sa diversité.

Certes, on observe la multiplication, depuis quinze ans, des études et ouvrages traitant de l'orthodoxie et l'intégrant comme facteur d'explication à d'autres dynamiques politiques ou sociales. Mais ces recherches sont dominées par des paradigmes et types d'approche sur lesquels il nous semble nécessaire de revenir. Une première approche consiste à envisager une "renaissance du religieux" à l'Est au sortir du communisme. L'épuisement de l'utopie communiste aurait laissé la place à un redéploiement spectaculaire du religieux, qu'aurait annoncé cette formule du Pape Jean-Paul II : " Dieu a gagné à l'Est ". Une seconde a une visée culturaliste, plus ou moins inspirée de la thèse du "choc des civilisations" formulée par Samuel Huntington. Elle consiste à définir une spécificité orthodoxe et à pointer une continuité de la culture orthodoxe comme mode de vie, à examiner l'incidence des "valeurs orthodoxes" sur la démocratisation et le pluralisme, sur la "modernisation" et I"'européanisation" des sociétés, à mesurer ainsi leur degré de sécularisation. Cette approche se rencontre chez certains "culturologues" (pour reprendre le terme consacré dans plusieurs pays de langue slave), mais aussi chez des acteurs religieux vantant les mérites d'une religion orthodoxe plus fidèle à la Tradition que les autres Églises chrétiennes. On la retrouve aussi chez certains transitologues et analystes du nationalisme à l'Est (en particulier dans les Balkans), ainsi que chez des internationalistes et chercheurs en géopolitique visant à redessiner

\footnotetext{
'Chercheurs, Centre d'Études et de Recherches internationales (CERI). Contacts : capelle.pogacean@cerisciences-po.org ; rousselet@ceri-sciences-po.org
} 
de nouvelles cartes mentales et symboliques après la chute du communisme et l'épuisement de la polarité Est-Ouest.

Ces lectures posent toute une série de difficultés. D'une part, la thèse du retour du religieux dans les sociétés post-communistes a été relativisée par des études à la fois quantitatives et qualitatives. De nouvelles recherches anthropologiques analysant les pratiques sociales et les univers de significations dans les sociétés post-communistes ont mis en lumière la diversité des logiques fondant le passage par le religieux et exploré les divers sens de la visibilité sociale de l'orthodoxie ${ }^{1}$. Des descriptions plus fines des rapports entre politique et religion montrent que le désenchantement du politique n'a pas débouché, de façon nécessaire, à un réenchantement religieux. D'autre part, il est nécessaire de poser un regard critique sur les représentations essentialisées, déshistoricisées et décontextualisées de l'orthodoxie véhiculées par les lectures culturalistes. Elles insistent de façon souvent très schématique, à partir de considérations théologiques et/ou d'une histoire trop mal connue, sur des accointances entre l'orthodoxie, présentée comme mystique et collectiviste, et le nationalisme, ou encore sur une "symphonie", mal définie, régissant les relations entre l'État et l'Église. Des études, mobilisant la sociologie des institutions et l'analyse de discours, ont pourtant souligné les tensions internes aux Églises et nuancé l'image d'institutions monolithes. Enfin, l'approche géopolitique ou géoreligieuse, pensée de façon trop essentialiste, tend à effacer les différences entre les orthodoxies dites nationales et à occulter les interactions ainsi que les logiques de rivalités et de compétitions qu'elles entretiennent. Elle ignore, par ailleurs, les processus de globalisation qui traversent les sociétés concernées, le redéploiement du croire orthodoxe et les diverses stratégies d'adaptation des institutions ecclésiales à l'heure de l'ouverture internationale du marché des biens du salut.

L'ensemble des articles présentés ici révèle une pluralité de logiques qui nourrissent dans l'espace balkanique les "politiques de l'orthodoxie", au gré des redéploiements stato-nationaux aux trajectoires diverses et des nouveaux enjeux européens. En Serbie, dès les années 1980, l'Église orthodoxe acquiert une forte visibilité sociale qui accompagne la réémergence du nationalisme, dans un contexte de crise politique, économique, sociale et idéologique ; alors que la population reste très sécularisée, cette institution religieuse tente aujourd'hui d'obtenir un statut d'Église d'État qui lui fut refusé jusqu'à présent (Yves Tomic). Dans d'autres pays de la région, des revendications identitaires provoquent, sur un même territoire, l'émergence ou la réémergence de nouvelles Églises et d'importants conflits de légitimité. C'est ainsi, par exemple,

\footnotetext{
${ }^{1}$ Voir à ce sujet en particulier Religion, State and Society, 33 (1), mars 2005, ainsi que " Les pratiques religieuses dans la Russie post-soviétique : entre tradition et renouveau ", Revue d'études comparatives EstOuest, 36 (4), décembre 2005 .
} 
qu'au Monténégro s'opposent l'Église orthodoxe serbe et l'Église autocéphale autoproclamée monténégrine; chacune investit à sa façon les sites religieux traditionnels et véhicule son idéologie propre, tandis que le gouvernement monténégrin semble prendre ses distances par rapport aux tensions ecclésiales (Amaël Cattaruzza, Patrick Michels).

Par delà les spécificités des trajectoires, les Églises orthodoxes évoluent aujourd'hui dans le cadre européen, ce qui suscite de nouveaux enjeux. Le Patriarcat de Constantinople, celui de Moscou et l'Église de Grèce apparaissent à Bruxelles comme des concurrents, aux actions faiblement coordonnées. Chacune de ces institutions a sa propre vision de l'Europe et des rapports que l'orthodoxie devrait entretenir au monde et aux autres religions. Le jeu est néanmoins complexe, cette rivalité s'accompagnant d'une coopération intraorthodoxe réaffirmée et de stratégies d'alliances entre Églises chrétiennes face au monde sécularisé (Bérengère Massignon).

La rivalité sur le plan européen a ainsi des conséquences sur la politique des Églises. En Grèce, elle provoque un activisme et un militantisme renouvelés tant à l'intérieur du pays que vers l'extérieur. L'Église d'Athènes tente de renforcer son poids dans la société grecque en multipliant, entre autres, les activités caritatives. Face à l'influence accrue du Patriarcat de Constantinople, elle se rapproche de Moscou et, dans un même élan de lutte contre l'indifférence religieuse, tend la main à Rome (Tassos Anastassiadis).

Les Églises orthodoxes affirment avec force leur inscription dans la Tradition et, face aux nouveaux défis, elles se tournent vers des répertoires d'action déjà utilisés dans d'autres contextes historiques. Mais le réemploi et la resémantisation des concepts anciens se conjuguent avec l'invention de nouvelles stratégies que les diffèrents textes de ce dossier contribuent à mettre en lumière. Confrontées au pluriel et à l'ouverture, les Églises orthodoxes sont aujourd'hui entrées dans un monde de négociations. 